\title{
Is Multicultural Effectiveness Related to Phrasal Knowledge in English as a Second Language?
}

\author{
Fanny Forsberg Lundell ${ }^{1 *}$, June Eyckmans ${ }^{2}$, Alexandra Rosiers², Klara Arvidsson ${ }^{1}$ \\ ${ }^{I}$ Department of Romance Studies and Classics, Stockholm University, SE- 10691 Stockholm, Sweden \\ ${ }^{2}$ Department of Translation and Communication, Ghent University, Groot-Britannienlaan 45, 9000 Ghent, Belgium \\ Corresponding Author: Fanny Forsberg Lundell, E-mail: fanny.forsberg.lundell@su.se
}

\section{ARTICLE INFO}

Article history

Received: November 10, 2017

Accepted: January 25, 2018

Published: March 01, 2018

Volume: 7 Issue: 2

Advance access: February 2018

Conflicts of interest: None

Funding: None

\begin{abstract}
The present study investigates the role of personality in language learning, with a special focus on the association between multicultural effectiveness and phrasal knowledge in L1 Dutch L2 English learners in Belgium ( $\mathrm{n}=97$ ). Results from the Multicultural Personality Questionnaire $(M P Q)$ (five personality dimensions) were associated with results from a rational cloze test, measuring productive phrasal knowledge. In addition, scores from grammar proficiency tests were also included, since language proficiency is known to be a strong predictor for phrasal knowledge. A regression analysis revealed significant associations between phrasal knowledge and the personality dimensions Flexibility and Openmindedness, when grammar proficiency was controlled for. This study adds to the growing body of evidence of associations between phrasal knowledge and personality, encouraging researchers to pursue this avenue with learners from different L1/L2 pairings, in different contexts of L2 acquisition.
\end{abstract}

Key words: Personality, Phrasal Knowledge, Formulaic Sequences, Multicultural Effectiveness, English as a Second Language, Individual Differences

\section{INTRODUCTION}

An increasing number of scholars recognize that phrasal knowledge or knowledge of formulaic language ${ }^{1}$ is one of the essential components of L2 proficiency (cf. Schmitt, 2013). Language use is, in many cases, not a product of the application of grammatical and lexical rules, but is largely formulaic in nature (Paquot \& Granger, 2012.). These formulaic utterances are, typically, language specific and thus constitute a challenge for the L2 learner, who often cannot translate them verbatim from his/her L1. Mastery of formulaic language tends to correlate with general language proficiency, as shown in several studies (e.g. Boers et al 2006; Lewis 2009; Forsberg Lundell \& Lindqvist, 2014). However, not only less advanced learners struggle with formulaic sequences (e.g. Forsberg, 2010; Forsberg Lundell et al. 2014; Bolly, 2009: Foster, Bolibaugh \& Kotula, 2014) - even if advanced learners use more formulaic sequences than the less advanced, they continue to pose problems at the most advanced levels of $\mathrm{L} 2$ learning. In addition, other studies show that mastery of formulaic language is subject to individual variation.

In two previous small-scale studies on very advanced L2 French, Forsberg Lundell and colleagues show that mastery of collocations (a sub-category of formulaic language) in L2 French is the vocabulary dimension which is the most sensitive to individual variation, with a higher standard deviation than other vocabulary tests, such as a c-test, a receptive deep knowledge test and a social routines test (Forsberg Lundell \& Lindqvist, 2014). In addition, this individual variation of mastery of collocations did not correlate with length of residence (LOR) in the target language country. It was suspected that the differences could be attributable to individual differences in psychological variables, since the learning of formulaic language is suggested to be linked to factors such as motivation, socio-cultural integration and aptitude (e.g. Adolphs \& Durow, 2004; Fitzpatrick \& Wray, 2006).

As a follow-up to that finding, Forsberg Lundell \& Sandgren (2013) investigated the same population and studied the associations between collocations, personality (Multicultural Personality Questionnaire) and language aptitude (LLAMA). The study (which will be discussed in greater detail below) showed that mastery of collocations did indeed correlate with two dimensions of the personality test, namely Cultural Empathy and Openmindedness. Furthermore, it also correlated with one of the sub-tests of the LLAMA aptitude test, i.e. LLAMA D which taps into sound recognition/phonetic memory. However, the studies were smallscale ( $\mathrm{n}=15$ and $\mathrm{n}=13)$ and targeted a specific population of language learners, i.e. L2 users who had spent considerable time in the target language country. In the present study, we wanted to follow up on the finding from Forsberg Lundell \& Sandgren (2013), this time focusing solely on the association between personality traits and formulaic language knowledge. It was deemed relevant to investigate whether this 
association would also be found in another type of learner population, in this case intermediate/advanced foreign language learners (in a formal setting). In addition, in order to further investigate the generalizability of the results, learners with a different L1 and a different L2 were investigated i.e. Flemish L1 learners of L2 English ( $\mathrm{n}=96)$. Accordingly, the study is guided by the following research question and hypothesis:

RQ: Is there an association between the personality dimensions of the MPQ and productive phrasal knowledge?

$\mathrm{H}$ : It is hypothesized that we will find a significant correlation between productive phrasal knowledge and some of the dimensions of the MPQ, more specifically Cultural Empathy and Openmindedness.

We will now address a theoretical framework for the acquisition of formulaic language, earlier research in the field of formulaic language in advanced L2 learning, as well as findings regarding the association between formulaic language mastery and psychological variables.

\section{BACKGROUND}

\section{A theoretical framework for the acquisition of formulaic language}

The present study is conducted within a theoretical perspective which views language acquisition largely as usage and frequency-dependent. Over the past two decades, usage-based perspectives on language acquisition have increasingly gained importance. Drawing on research from cognitive psychology, such as connectionist models, N.C. Ellis (2008) and Bybee (2008) among others, propose that it is an individual's experience with language that will model his or her language use, that language per se emerges in use and that an individual will be very sensitive to the frequency with which elements occur in the input. While grammar, for example, is not a fixed set of pre-existing rules, for the individual, grammatical regularities are extracted and emerge from the many exemplars that every individual has stocked through processes of chunking. This is why, according to N.C. Ellis (2002a, 2002b), the acquisition of formulaic sequences serves two ends: they enable the extraction of creative rules and their use is a prerequisite for fluency and idiomaticity. This means that "formulas can break down" (N.C. Ellis 2002b), but there is, at the same time, a huge processing gain in keeping them as chunks. When it comes to the learning mechanisms of the sequences, N.C. Ellis suggests that there are two different modes of learning: one is initial, holistic chunk learning and the other is incremental learning. In other words, formulaic sequences need gradual reinforcement in order to become automatized and entrenched in the mental lexicon, in N.C. Ellis's own words: "nativelike fluency and idiomaticity require an awful lot of figuring out which words go together" (2002a: 157).

N.C. Ellis $(2006,2008)$ develops his theorizing on frequency effects with special regard to second language acquisition. Most people would probably agree that acquiring an L2 and an L1 are two different processes. N.C. Ellis (2008) suggests that the child acquiring its' L1 can be seen as a tabula rasa whereas the L2 learner, already in possession of a linguistic system, can consequently be seen as a tabula repleta. He means that the same mechanisms that can explain the success of L1 acquisition can also explain why many L2 learners fail in attaining nativelike levels of their L2. Since language learning is based on entrenchment according to N.C. Ellis, the entrenchment of the L1 system can sometimes interfere with the emerging L2 system. Usage-based models of formulaic language acquisition justly state the important role of frequency and exposure, but also of L1 influence. Such an approach to language acquisition can easily be combined with the study of individual differences, since individuals differ in how they create opportunities for exposure and how they perceive and process input. This is also why we can expect to find individual variation in phrasal knowledge being related to an individual's personality traits.

\section{Phrasal knowledge in $\mathrm{L} 2$ acquisition}

Following N.C. Ellis's reasoning above, the incremental acquisition of phrases which comes so naturally to the L1 user poses a serious challenge for the L2 learner who simply does not receive sufficient L2 input for associations between words to become strong enough to guarantee their storage as unitary combinations in the lexicon (Eyckmans, 2010). This might explain why highly proficient language learners are so easily distinguished from native speakers (Pawley \& Syder, 1983; Boers \& Lindstromberg, 2009). Notwithstanding the time and effort advanced learners have spent on learning their second language in a formal setting, they often fail to combine words in idiomatic ways. Mistakes like *do an effort (instead of make an effort) are often attested in the speech and writing of advanced language learners (Nesselhauf, 2003) and are probably the result of transferring L1 collocational patterns to L2. Furthermore, research on phrasal knowledge has shown that it is a late feature in L2 learning, and that it is an aspect that often seems to set native speakers apart from non-native speakers both in terms of quantity and quality (e.g. Arnaud and Savignon 199, Lewis 2009, Mizrahi \& Laufer 2010, 2011, Forsberg Lundell \& Lindqvist, 2012). Mizrahi \& Laufer (2011), for example, analyzed lexical use in free writing and found that highly advanced learners of L2 English achieved native-like levels in terms of other lexical measures, viz. lexical richness (as measured by the Lexical Frequency Profile, Laufer \& Nation, 1995) and lexical variation (as measured by the Type/Token Ratio), but not regarding the use of collocations. Durrant \& Schmitt (2009) examined the use of highly frequent English collocations by native and non-native speakers, studying written texts. They focused on noun-noun and adjective-noun combinations. The results showed that the native writers used more low-frequency combinations than non-native writers did. Durrant \& Schmitt (2009: 175) concluded that: "Advanced non-native phraseology differs from that of natives not because it avoids formulaic language altogether, but because it overuses high-frequency collocations and underuses the lower-frequency, but strongly-associated, pairs characterized by high mutual information scores. Since the latter kind appear (intuitively, and on the psycholinguis- 
tic evidence presented by Ellis et al) to be highly salient for native speakers, their absence may be what creates the feeling that non-native writing lacks 'idiomaticity'."

Being a difficult feature to acquire, the effort and time invested by L2 learners in doing so, however, seems worthwhile. The benefits of phrasal competence for language proficiency have been attested in several research papers. The use of phrases has been shown to lead to more fluent speech in native speakers as well as second language learners, not only because phrases usually do not contain pauses or hesitations but also because they are uttered faster than other parts of sentences (Bybee 2002). In studies in which the fluency of second-language-learner speech was evaluated by blind judges, it was found that the perceived fluency of the participants correlated significantly with the number of phrases they had used in their discourse (Boers et al., 2006; Eyckmans et al., 2007; Stengers, 2009).

Evidence of the contribution of phrasal knowledge to fluency also comes from psycholinguistic research in which eye-tracking was used to monitor participants' eye movements when reading stretches of English text containing phrases or synonymous free-word combinations. Native as well as non-native speakers of English were found to read the stretches of text containing phrases faster, regardless of whether the phrases were used literally or figuratively in the text (Conklin \& Schmitt, 2008). These results seem to suggest that phrasal knowledge also facilitates fluency in the reception of language.

Apart from the affordances of phrase competence for fluency, the beneficial impact of phrasal knowledge on the lexical richness and syntactic complexity of learner's interlanguage has been corroborated (Eyckmans et al., 2006; Stengers, 2009). In both studies, significant positive correlations were found between the number of lexical phrases used by language learners in an oral interview and the scores they received from blind judges for lexical richness and syntactic complexity.

It can, consequently, be concluded that phrasal knowledge is generally a feature in L2 acquisition learnt late, that has an important bearing on L2 proficiency, in terms of fluency, idiomaticity and complexity.

\section{The Association between Phrasal Knowledge and Psychological Variables in SLA}

As mentioned above, the main reason for conducting Forsberg Lundell \& Sandgren (2013) was that the standard deviation in a group of advanced Swedish L1 French L2 users was remarkably high for a collocation test, compared to three other lexical tests (6.1 compared to 1.9, 1.6 and 3.1) (cf. Forsberg Lundell \& Lindqvist, 2014). An even more intriguing fact was that the person who had the highest score on this test was a non-native speaker and not a native speaker of French (NNS were compared to NS). Since LOR did not show to be relevant as an explanatory factor, it seemed plausible to assume that other individual factors would be relevant to investigate. A study was designed which examined the association between a collocation test, a grammatical judgment test (as a comparison to colloca- tional knowledge), a personality test - the MPQ (Multicultural Personality Questionnaire, Van der Zee \& Van Oudenhoven, 2002, see below) and an aptitude test, the LLAMA aptitude test (Meara, 2005). There was, of course, a reason for choosing these individual factors specifically. Language aptitude is, after age of onset, the individual factor with the highest explanatory value (Granena \& Long, 2013, p. 1) in adult second-language acquisition. Speciale, Ellis \& Bywater showed back in 2004 that the learning of lexis and collocation was associated with phonological memory, which suggests that these language components are specifically linked to at least some components of aptitude. The reason for including the second individual factor, personality, in relation to formulaic language, was that formulaic language tends to involve word combinations that not only need to be remembered as whole units (thus requiring good phonological memory) but are also often idiomatic i.e. specific to a certain language and culture. For the acquisition of phonology, it has been found by Segalowitz, Gatbonton \& Trofimovich (2009) that identity and group affiliation are important factors. It was argued in Forsberg Lundell \& Sandgren (2013) that personality could also be an important variable in this latter study, since an open-minded, flexible personality could be linked to a more flexible identity. Guiora and colleagues' (e.g. Guiora, Brannon \& Dull, 1972) controversial results from the 1970s were also a source of inspiration: higher empathy and thinner ego boundaries were suggested to be associated with better foreign-language pronunciation. The two studies mentioned investigate pronunciation, but similar effects could also be found for formulaic language. An open-minded, flexible personality would help the learner to accept linguistic expressions in the L2, without rejecting them because they are different from L1 linguistic (and cultural) conventions. It was thus deemed interesting to include a personality test which would account for the individual's capacity to adapt and open up to a new language and culture. Participants in the study were 13 late learners Swedish L1 French L1, average LOR of 14.5 years in France. The result showed that the collocation test (and not the grammatical judgment test (GJT)) correlated significantly with two of the five personality dimensions in the MPQ: Cultural empathy $(\mathrm{r}=0.62)$ and Open-mindedness $(\mathrm{r}=0.57)$. It has to be said that the results are based on a small sample, but the associations are stronger than normally obtained for personality and language learning, where common results are closer to $\mathrm{r}=0.20-0.30$ (cf. Dewaele, 2013). In addition, an association was also found between the collocation test and a subtest of the LLAMA test, namely LLAMA D, which, interestingly, measures phonetic memory $(\mathrm{r}=0.58)$. What makes these results even more interesting is that we discover a few similar findings in the last five years of SLA research. Granena (2013a), focusing on language aptitude, also found a link between collocations/lexis and LLAMA D (cf. Forsberg Lundell \& Sandgren, 2013). In Granena (2013b), the author focuses on validating the LLAMA test. She proposes that LLAMA D is associated with implicit learning mechanisms. Bolibaugh \& Foster (2013), also interested in 
the role of language aptitude, found a correlation between phonological memory and the capability to detect non-nativelike word combinations in a text. Personality has not been studied to date in relation to formulaic language (besides Forsberg Lundell \& Sandgren, 2013), but it is interesting to note that Kormos (2013:147) stresses the importance of personality for successful adult language learning: "One might even argue that the extent to which learners create opportunities for themselves and seize opportunities inherent in naturalistic learning settings to receive input, engage in interaction and produce output is, in all likelihood, better predicted by affective and conative components of aptitude than by learners' cognitive characteristics". Following Kormos's proposals, it can be assumed that personality plays a more important role in naturalistic learning than in instructed learning, since personality would be linked to taking advantage of opportunities of authentic interaction and hence L2 exposure. However, the link between successful acquisition of formulaic language and personality could also be relevant to instructed SLA. If the acquisition of formulaic sequences can largely be seen as the acquisition of new linguistic habits, then personality traits such as Open-mindedness, Cultural Empathy and Flexibility would also be useful for a learner in a formal setting.

\section{METHOD}

\section{Definition of Phrases}

In the many corpus linguistic analyses that have demonstrated that language is rich in collocational restrictions and semantic prosodies, it has also been attested that this phraseological phenomenon comes in a variety of forms and fulfills a variety of functions. This diversity explains why a plethora of terms have been used in the literature both for chunks in general (e.g., multiword units, holophrases, phrasemes, formulae, set phrases, lexical bundles, prefabricated routines, ready-made utterances, formulaic sequences and so on) and various sub-classes of chunk (such as phrasal verbs, multi-word verbs, figurative idioms and dead metaphors; for more, see Wray, 2000). The identification of phrases in text is not an easy task. Gries \& Divjak (2012) put forward that a phrase is the co-occurrence of a lexical item and one or more additional linguistic elements which functions as one semantic unit and whose frequency of co-occurrence is larger than expected on the basis of chance. However, in any corpus linguistic study, the identification of formulaic phrases will depend on the kind of lexicometrics that was used.

Although Forsberg Lundell \& Sandgren (2013) opted for a collocation test in their previous study, it was decided to not restrict the measurement of phrasal knowledge to collocations in this study. Since we know that half of written text is made up of formulaic sequences and that the proportion is likely to be even larger in spoken discourse (Butler, 2005: 223; Erman and Warren, 2000), we opted for a broader perspective in which discourse markers, idiomatic expressions, standardized similes and genre-typical clichés were included. The specific approach is that of Erman \& Warren (2000) who define phrases in the following way:
A prefab is a combination of at least two words favored by native speakers in preference to an alternative combination which could have been equivalent had there been no conventionalization (2000: 31). The criterion used by these authors for identifying prefabs is that of 'restricted exchangeability'. This means, in the words of Erman \& Warren (2000: 32) "that at least one member of the prefab cannot be replaced by a synonymous item without causing a change of meaning or function and/or idiomaticity". In order to measure the learners' phrasal knowledge from a broader perspective, a contextualized test format seemed most appropriate. A rational cloze test containing gaps that target phrasal knowledge appeared to be an adequate choice.

\section{Cloze Test: Format and Identification of Phrases}

The text that was used to construct the rational cloze tests was taken from the newspaper The Guardian. Itwas considered to reflect general journalistic discourse and was estimated to align with the language proficiency level of the learner group (around $\mathrm{C} 1$ of the CEFR). The text counted 547 words. An analysis with the software Lextutor showed that the text contained $79.96 \% \mathrm{~K} 1$ words (highest frequency band, 1-1000), 5.28\% K2 words, 5.10\% AWL (words from the academic word list) and $9.65 \%$ Off list words (words that are not present in the corpus of frequency lists used). Learners at a $\mathrm{C} 1$ level are supposed to understand basically any text and given the considerable percentage of $\mathrm{K} 1$ words, this text was probably easy for the learners to understand. However, productive and passive knowledge are two different things in terms of difficulty and so is single word knowledge and phrasal knowledge. Schmitt (2014) argues that productive knowledge of formulaic knowledge is one of the most challenging ways of assessing L2 vocabulary.

In the text, the formulaic phrases were identified and each time one key element of the phrase was deleted in order to create a gap-fill format (following Erman \& Warren's (2000) definition, see above). This resulted in a selection of phrases that belong to diverse phrase types: prepositional verbs (e.g. to fall for someone) collocations (e.g. to admit defeat), idiomatic expressions (e.g. how the cookie crumbles). More specifically, the identification process was the following: one of the researchers, basing herself on Erman \& Warren's definition, checked the text for word combinations that would correspond to this definition. To check for 'restricted exhangeability' one of the words was removed and replaced by a synonym. If that combination was judged to change in meaning or lose idiomaticity, it was qualified as a formulaic phrase. An example is one of the formulaic phrases in the text below, at play. If you change one of the words to a synomym, you may end up with a combination such as at *joke, which is clearly not a conventionalized combination. In order to enhance the reliability of the target material, a second researcher was asked to double check the idiomatic nature of the selected phrases. The cloze test consisted of 35 items and obtained a Cronbach's alpha of .995 for its 96 test takers. Below follows a sample from the test:

This disturbing picture of people having no conscious control over whom they love or loathe .................... as 
no surprise to Julian Boon, lecturer in personality at Leicester University. He believes that when it comes to relationships, basic evolutionary principles are at (article from The Guardian)

\section{Grammar Proficiency Tests}

In the present study, it was decided to control for the general proficiency of the learners, since research has shown that phrasal knowledge and language proficiency are closely related. In order to obtain an independent measure of proficiency, it was decided to use scores from a grammar proficiency test. It can be argued that it only represents one dimension of language proficiency. However, grammar tests are often used as language proficiency test and they were deemed to constitute a relevant point of comparison. The participants' grammatical competence was measured by means of an extensive written grammar test targeting the use of tenses, modals and conditionals. The test was scored on a total of 20. Scores on the grammar proficiency test will be used as a control variable.

\section{MPQ (The Multicultural Personality Questionnaire)}

The Multicultural Personality Questionnaire (MPQ) is a personality test developed by van der Zee \& van Oudenhoven (2002). As the authors state themselves: "the MPQ questions refer to behavior in multicultural situations" (2002, p. 680), proposing that the Five factor model does not cover all the traits relevant for multicultural effectiveness and that a slightly different test is motivated. Thus MPQ is used to predict an individual's capacity to function in new cultural environments. Like the Five factor model, the instrument has five scales but those of the MPQ are labelled Cultural empathy, Open-mindedness, Flexibility, Social initiative and Emotional stability. Cultural empathy, Open-mindedness and Flexibility are linked to the domain of intercultural interaction, while Social initiative and Emotional stability are connected to personal adjustment.

\section{Participants and Data Collection}

The participant group included 97 Dutch native speakers in Belgium, studying English as a foreign language at university level at the end of their first year. These participants were predominantly female, with 68 female students compared to 29 male students. Their level of proficiency was assumed to be around $\mathrm{C} 1$ level in the Common European Framework of Reference as they had already studied English for 6 years on average.

The MPQ was administered in paper and pencil form in class. Although there was no time limit, students were advised not to ponder over the questions for too long. Students could not partake anonymously, as the results needed to be related to the gap test data and the grammar data. They were, however, assured that their results would be treated confidentially. The data were made anonymous after analysis and participation was entirely voluntary.

\section{Statistical Analyses}

For the investigation of our research question, descriptive statistics was used to characterize the data. All analyses were carried out with the use of statistical software (The SAS system for Windows 9.4 (SAS Institute Inc., Cary, NC, USA.) and the $5 \%$ level of significance were considered. Pearson correlation analyses was the most evident statistical analysis to run, with the Cloze test as dependent variable and MPQ total, as well as the separate personality dimensions, as independent variables. Since it was suspected that grammar proficiency would constitute a potentially important co-variate, we also ran a regression analysis, controlling for proficiency. The analysis chosen for regression was a step-wise model. In the case of a statistically significant result, the probability value ( $p$-value) has been given.

\section{RESULTS}

Below follows a description of the results, both descriptive statistics of the different tests and results from correlations and regression analyses.

\section{Descriptive Statistics for the Different Tests}

First, descpritive statistics for the results on the cloze test, the grammar test and the MPQ test are accounted for. The average score on the Cloze test was 22.2 out of 30 and on the Grammar test 8.7 out of 20 .

Table 1. Descriptive statistics of the different tests of the participants $(n=97)$

\begin{tabular}{lccccc}
\hline Variable & Mean & Standard deviation & Median & Minimum & Maximum \\
\hline CLOZE & 22.2 & 3.9 & 23.0 & 14.0 & 32.0 \\
GRAM & 8.7 & 3.08 & 9.0 & 4.0 & 20.0 \\
MPQ Tot & 129.5 & 15.0 & 129.0 & 31.0 & 167.0 \\
CultEmp & 31.3 & 3.7 & 32.0 & 19.0 & 39.0 \\
Flex & 22.7 & 4.8 & 23.0 & 10.0 & 32.0 \\
SocIni & 25.7 & 5.3 & 26.0 & 10.0 & 38.0 \\
Open & 26.7 & 4.0 & 26.0 & 16.0 & 37.0 \\
EmoSt & 22.9 & 5.7 & 23.0 & 9.0 & 35.0 \\
\hline
\end{tabular}




\section{The Association Between Phrasal Knowledge and Multicultural Effectiveness}

In order to examine the relationship between the cloze test and the MPQ, several statistical tests were run. The first step consisted of a correlation analysis using the Pearson correlation coefficient, which did not yield any significant correlations (see Table 2).

Table 2. Pearson correlation between Cloze, MPQ total and the different personality dimensions of the MPQ

\begin{tabular}{lc}
\hline $\begin{array}{l}\text { Pearson correlation coefficients Prob }>|\mathbf{r}| \\
\text { under H0: Rho }=\mathbf{0} \text { Number of observations }\end{array}$ & \\
\hline \multicolumn{2}{l}{ CLOZE } \\
\hline MPQ Total & $\mathrm{r}=0.07691$ \\
& $\mathrm{p}=0.4637$ \\
& 93 \\
CultEmp & $\mathrm{r}=0.03678$ \\
& $\mathrm{p}=0.7178$ \\
Flex & 99 \\
& $\mathrm{r}=0.18302$ \\
SocIni & $\mathrm{p}=0.0698$ \\
& 99 \\
Open & $\mathrm{r}=-0.15646$ \\
& $\mathrm{p}=0.1259$ \\
& 97 \\
EmoSt & $\mathrm{r}=0.11579$ \\
& $\mathrm{p}=0.2587$ \\
& 97 \\
& $\mathrm{r}=0.12674$ \\
& $\mathrm{p}=0.2210$ \\
& 95 \\
\hline
\end{tabular}

Table 3. Stepwise regression analysis for Cloze, Flexibility and Grammar proficiency

\begin{tabular}{lc}
\hline Dependent variable: CLOZE & 103 \\
\hline Number of observations read & 95 \\
Number of observations used & 8 \\
\hline
\end{tabular}

Stepwise selection: Step 1

Variable GRAM entered: R-square $=0.1949$ and C $(p)=6.2442$
Since proficiency is a well-known covariate for phrasal knowledge, we suspected that it might constitute an important variable to control for. We then proceeded to a regression analysis, controlling for grammar proficiency. This analysis explains how much of the variance in the cloze test can be explained by the MPQ when proficiency is controlled for. A step-wise regression analysis was subsequently conducted. Significant results were found between the Cloze test and Flexibility $(p=0.0243)$ and between the Cloze test and Open-mindedness ( $\mathrm{p}=0.0183)$, as can be seen in Tables 3-12 below. Associations between MPQ and personality variables thus only appear when proficiency is controlled for, suggesting the strong explanatory power of grammar proficiency for phrasal knowledge and the interconnection between proficiency and personality.

Tables 3, 4, 5, 6, 7 . Stepwise regression analysis for Cloze, Flexibility and Grammar proficiency.

Tables 8, 9, 10, 11, 12. Stepwise regression analysis for Cloze, Open-mindedness and Grammar proficiency.

\section{DISCUSSION AND CONCLUSION}

In the present study, our main interest was to establish whether certain personality dimensions were associated with the mastery of phrasal knowledge. Based on earlier findings, it was hypothesized that phrasal knowledge would be associated especially with the dimensions Cultural Empathy and Open-mindedness of the MPQ. On the basis of the statistical analyses of our data, the hypothesis can be said to be partly confirmed. A Pearson correlation analysis did not yield any significant results, whereas the regression analysis controlling for proficiency yielded significant results for Flexibility and Open-mindedness, the last dimension having been associated with phrasal knowledge. It is interesting that Flexibility gave rise to significant results. It is clearly a personality dimension, which could be of use when acquiring word combinations which are not conventionalized in your first language. In addition, the study highlighted the importance of general proficiency for phrasal knowledge, since significant associations between phrasal competence and personality dimensions only appeared when grammar proficiency was controlled for.

\begin{tabular}{lccccc}
\hline Analysis of variance & & & & \\
\hline Source & DF & Sum of squares & Mean square & F value & 22.51 \\
\hline Model & 1 & 291.56908 & 291.56908 & & $<0.0001$ \\
Error & 93 & 1204.78882 & 12.95472 & & \\
Corrected total & 94 & 1496.35789 & & & \\
\hline
\end{tabular}

\begin{tabular}{lccccc}
\hline Variable & Parameter estimate & Standard error & Type II SS & F value & Pr $>$ F \\
\hline Intercept & 17.22649 & 1.11567 & 3088.49504 & 238.41 & $<0.0001$ \\
GRAM & 0.57374 & 0.12094 & 291.56908 & 22.51 & $<0.0001$ \\
\hline
\end{tabular}

Stepwise selection: Step 2

Variable flex entered: R-square 0.2383 and $C(p)=3.0000$ 


\begin{tabular}{lccccc}
\hline Variable & Parameter estimate & Standard error & Type II SS & F value & Pr $>$ F \\
\hline Intercept & 13.08208 & 2.11321 & 474.80395 & 38.32 & $<0.0001$ \\
Flex & 0.17609 & 0.07690 & 64.97209 & 5.24 & 0.0243 \\
GRAM & 0.58883 & 0.11845 & 306.15607 & 24.71 & $<0.0001$ \\
\hline
\end{tabular}

\begin{tabular}{lc}
\hline Dependent variable: CLOZE & 103 \\
\hline Number of observations read & 94 \\
Number of observations used & 9 \\
Number of observations with missing values & \\
\hline
\end{tabular}

Stepwise selection: Step 1

Variable GRAM entered: R-square $=0.2003$ and $C(p)=6.7782$

\begin{tabular}{lccccc}
\hline Analysis of variance & & & & \\
\hline Source & DF & Sum of squares & Mean square & F value & 23.05 \\
\hline Model & 1 & 299.61925 & 299.61925 & 13.00136 & \\
Error & 92 & 1196.12543 & & & \\
Corrected total & 93 & 1495.74468 & & \\
\hline
\end{tabular}

\begin{tabular}{lccccc}
\hline Variable & Parameter estimate & Standard error & Type II SS & F value & Pr $>$ F \\
\hline Intercept & 17.08649 & 1.13076 & 2968.59665 & 228.33 & $<0.0001$ \\
GRAM & 0.58622 & 0.12211 & 299.61925 & 23.05 & $<0.0001$ \\
\hline
\end{tabular}

Stepwise selection: Step 2

Variable open entered: R-square $=0.2481$ and $C(p)=3.0000$

\begin{tabular}{|c|c|c|c|c|c|}
\hline \multicolumn{6}{|c|}{ Analysis of variance } \\
\hline Source & DF & Sum of squares & Mean square & F value & $\operatorname{Pr}>$ F \\
\hline Model & 2 & 371.03475 & 185.51738 & 15.01 & $<0.0001$ \\
\hline Error & 91 & 1124.70993 & 12.35945 & & \\
\hline Corrected total & 93 & 1495.74468 & & & \\
\hline
\end{tabular}

\begin{tabular}{lccccc}
\hline Variable & Parameter estimate & Standard error & Type II SS & F value & Pr $>$ F \\
\hline Intercept & 10.56666 & 2.92782 & 160.98561 & 13.03 & 0.0005 \\
Open & 0.22284 & 0.09270 & 71.41550 & 5.78 & 0.0183 \\
GRAM & 0.64944 & 0.12193 & 350.62179 & 28.37 & $<0.0001$ \\
\hline
\end{tabular}

Our results lend some support to those obtained by Forsberg Lundell \& Sandgren (2013), indicating that it is worthwhile pursuing studies on the relationship between phrasal knowledge and personality. On a more detailed note, the results confirm that Open-mindedness is associated with phrasal knowledge, and that other dimensions of the MPQ may be as well, not least Flexibility. In this context, Flexibility could be interpreted as the tendency to interpret novel linguistic expressions/conventions as something positive (rather than something to reject), and adapt one's linguistic habits accordingly.

On a more general note, we believe that our study encourages further research into the association between personality variables and language learning. In a special chapter synthesizing the work on personality and SLA, Dewaele (2013: 1) states that "the effect of some personality traits can remain invisible in some situations or tasks, but may surface in other circumstances. It is thus not surprising that personality variables are typically linked to small effect sizes on L2 variables." Dörnyei \& Ryan (2015) also discuss the relative shortcomings thus far for research on personality variables in SLA. They suggest that there is a puzzling gap between teachers' and learners' intuitions about the important part played by personality in the language-learning process and the relatively poor results when trying to investigate this relationship. These authors propose two main causes of problems of this research so far: 1) research aiming at associating single, isolated personality traits (such as Extraversion) with simplistic measures of learning outcome or L2 proficiency generally fail, and 2) higher-order personality traits, which have traditionally been investigated, seem less suc- 
cessful to include than lower-order personality traits (such as Emotional Intelligence or Empathy).

By means of the research design of the present study, we believe that we have provided some features that might be missing in some earlier research, the most important factor being our choice of dependent variable. Formulaic language is known to be acquired late and is also known to be subject to an important degree of individual variation (see Introduction and Background). Acquiring formulaic sequences in an L2 implies that the learner has to combine words in a different way than in the L1. This might require an open-minded approach towards the linguistic conventions of the target language. These are probably a few of the reasons why they constitute a fine-tuned linguistic measure to include in research on the relationship between personality and SLA.

The results of the present study encourage future research into the relationship between phrasal knowledge and personality traits. In addition, we suggest that it would be worthwhile to investigate more advanced levels or, if less advanced, groups in a study-abroad context, which deal with multicultural experiences to a higher degree. We recognize that language proficiency could have been measured in a more complex manner, and this constitutes one of this study's limitations. Vocabulary tests or CEFR-related tests could be valuable in this respect. Language proficiency is clearly an important co-variate to phrasal knowledge, so it should be measured by various means. In sum, the present study suggests that personality variables are well worth pursuing in SLA, but the relationship needs to be investigated in more learning settings - with different L1/L2 pairings and different proficiency levels.

\section{END NOTE}

1 Phrasal knowledge and formulaic language knowledge are used as synonyms in this paper.

\section{REFERENCES}

Abrahamson, N. \& Hyltenstam, K. (2008). The robustness of aptitude effects in near-native second language acquisition. Studies in Second Language Acquisition, 30(4), 481-509.

Adolphs, S. \& Durow, V. (2004). Socio-cultural integration and the development of formulaic sequences. In Schmitt, N. (ed), Formulaic Sequences: Acquisition, processing, use. (pp. 107-126) Amsterdam: Benjamins.

Arnaud, P. J. L., \& Savignon, S. J. (1997). Rare words, complex lexical units and the advanced learner. In J. Coady \& T. Huckin (Eds.), Second Language VocabularyAcquisition (pp. 157-173). Cambridge: Cambridge University Press.

Boers, F. \& Lindstromberg, S. (2009). Optimizing a lexical approach to instructed second acquisition. Basingstoke: Palgrave MacMillan.

Boers, F., J. Eyckmans, J. Kappel, H. Stengers, and M. Demecheleer. (2006). Formulaic sequences and perceived oral proficiency: putting a lexical approach to the test. Language Teaching Research, 10(3), 245-261.
Bolibaugh, C. \& Foster, P. (2013). Memory-based aptitude for nativelike selection. The role of phonological shortterm memory. In Granena, G. and Long, M. (Eds.), Sensitive periods, language aptitude and ultimate L2 attainment. (pp. 205-230). Amsterdam: John Benjamins.

Bolly, C. (2009). The acquisition of phraseological units by advanced learners of French as an L2: High frequency verbs and learner corpora. In Labeau, E. \& Myles, F. (Eds), The advanced learner variety: the case of French. (pp. 5-27). Oxford: Peter Lang.

Butler, C.S. (2005). Formulaic language. In Butler, C.S., de los Angeles Gómez-Gonzales, M. \& Doval-Suárez, S.M. (eds), The Dynamics of Language Use. Amsterdam: John Benjamins.

Bybee, J. (2002). Phonological evidence for exemplar storage of multiword sequences. Studies of Second Language Acquisition 24 (2). 215-221.

Deconinck J., Eyckmans, J. \& F. Boers (2009) Music to their ears? Assessing learners' sensitivity to the form of multi-word units. In Koole T., Nortier J. \& Tahitu B. (Eds.), Artikelen van de Zesde Anéla Conferentie (p. 6372) Delft: Eburon.

Dewaele, J-M. (2013). Personality in Second Language Acquisition. In: Chapelle, C.A (ed.), The Encyclopedia of Applied Linguistics, Wiley-Blackwell.

Dörnyei, Z. \& Ryan, S. (2015). The Psychology of the language learner revisited. New York: Routledge.

Ellis, N. C. (2002a). Frequency effects in language processing. Studies in Second Language Acquisition 2(4). $143-188$.

Ellis, N. C. (2002b). Reflections on frequency effects in language processing. Studies in Second Language Acquisition, 24(2), 297-339.

Ellis, N.C. (2005). At the interface: dynamic interactions of explicit and implicit language knowledge. Studies in Second Language Acquisition, 27, 305-352.

Ellis, N. C. (2006). Selective attention and transfer phenomena in L2 acquisition: Contingency, cue competition, salience, interference, overshadowing, blocking and perceptual learning. Applied Linguistics, 27(2). 164-194.

Ellis, N. C. (2008). Usage-based and form-focused language acquisition: The Associative learning of constructions, learned attention and the limited L2 endstate. In P. Robinson \& N. C. Ellis (Eds.), Handbook of Cognitive Linguistics and Second Language Acquisition (pp. 372406). New York, NY: Routledge.

Erman, B. \& Warren, B. (2000). The idiom principle and the open choice principle. Text, 20(1), 29-62.

Eyckmans J. (2010) Phrase-noticing or phrase-learning: A question of semantics? In: Moreno Jaén M., Serrano Valverde F. \& M. Calzada Pérez (Eds.) Exploring New Paths in Language Pedagogy Lexis and Corpus-Based Language Teaching (p.31-42). London: Equinox Publishing Ltd.

Eyckmans J., Boers F. \& Stengers H. (2007) Identifying chunks: who can see the wood for the trees? Language Forum, 33(2), 85-100.

Fitzpatrick, T. \& Wray, A. (2006). Breaking up is not so hard to do. Individual Differences in L2 memorisation. Cana- 
dian Modern Language Review, 63(1), 35-57.

Forsberg, F. and Fant, L. (2010). Idiomatically speaking effects of task variation on formulaic language in high proficient users of L2 French and Spanish. In: Wood, D. (ed.), Perspectives on formulaic language in acquisition and communication. New York: Continuum. 47-70.

Forsberg Lundell, F. and Lindqvist, C. (2014). Lexical aspects in very advanced L2 French. Canadian Modern Language Review 70/1, 28-49.

Forsberg Lundell, F., Bartning, I., Engel, H, Gudmundsson, A, Hancock, V. and Lindqvist, C . (2014). Beyond advanced stages in high-level spoken L2 French. Journal of French Language Studies, 24(2), 1-26.

Forsberg Lundell, F. \& Lindqvist, C. (2012). Vocabulary development in advanced L2 French - do formulaic sequences and lexical richness develop at the same rate? LIA (Langage, Interactions, Acquisition), 3(1), p. 73-92.

Forsberg Lundell, F., and Sandgren, M. (2013). High-level proficiency in late L2 acquisition - Relationships between collocational production, language aptitude and personality. In: Granena, G. and Long, M. (eds.), Sensitive periods, aptitudes and ultimateattainment in L2. Amsterdam: Benjamins. 231-256.

Foster, P. \& Bolbaugh, C. \& Kotula, A. (2014). Knowledge of nativelike selections in a L2. Studies in Second Language Acquisition, 36(1), 101-132.

Granena, G. (2013a). Cognitive aptitudes for second language learning and the LLAMA aptitude test. In Granena, G. and Long, M. (eds.), Sensitive periods, language aptitude and ultimate L2 attainment. (pp. 105-129). Amsterdam: John Benjamins.

Granena, G. (2013b). Reexamining the robustness of aptitude in second language acquisition. In Granena, G. and Long, M. (eds.), Sensitive periods, language aptitude and ultimate L2 attainment. (179-205).Amsterdam: John Benjamins.

Granena, G. and Long, M. (Eds.) 2013. Sensitive periods, language aptitude and ultimate L2 attainment. Amsterdam: John Benjamins.

Guiora, A. Z., Brannon, R. C. and Dull, C.Y. (1972). Empathy and second language learning. Language Learning 22 (1), 111-130.

Gries, S. \& Divjak, D. (Eds) (2012). Frequency effects in language learning and processing. Berlin: Mouton de Gruyter.

Kaufman, S.B., De Young, C.G., Gray, J.R., Jiménez, L., Brown, J. Mackintosh, J. (2010). Implicit learning as an ability. Cognition, 116(3), 321-340.

Kormos, J. (2013). New conceptualizations of language aptitude in second language attainment. In Granena, G. and Long, M. (Eds.), Sensitive periods, language aptitude and ultimate L2 attainment. (pp. 131-152) .Amsterdam: John Benjamins.

Lewis, M. (2009). The Idiom Principle in L2 English: Assessing elusive formulaic sequences as indicators of $i d-$ iomaticity, fluency, and proficiency. Saarbrücken: VDM Verlag.
Mizrahi, E., \& Laufer, B. (2010). Lexical competence of highly advanced L2 users: is their collocation knowledge as good as their productive vocabulary size? Paper presented at Eurosla 20, Reggio Emilia, Italy.

Mizrahi, E., \& Laufer, B. (2011). Does one need a native-like productive lexical knowledge to pass for a native writer? Paper presented at Eurosla 21, Stockholm, Sweden.

Nesselhauf, N. (2003). The use of collocations by advanced learners of English and some implications for teaching. Applied Linguistics, 24(2), 223-242.

Nesselhauf, N. 2005. Collocations in a learner corpus. Amsterdam: John Benjamins.

van Oudenhoven, J.P., van der Zee, K.I. (2002). Predicting multicultural effectiveness of international students: The Multicultural Personality Questionnaire. International Journal of Intercultural Relations 26. 679-694.

van der Zee, K.I. Van Oudenhouven, J.P, Ponterotto, J.G. \& Fietzer, A.W. (2013). Multicultural Personality Questionnaire: Development of a short from. Journal of Personality Assessment, 95(1), 118-124.

Paquot, M. \& Granger, S. (2012). Formulaic language in learner corpora. Annual Review of Applied Linguistics, 32, 130-149.

Pawley, A. \& Syder, F. (1983). Two puzzles for linguistic theory: nativelike selection and nativelike fluency. In Richards, J.C. \& Schmidt, R. (eds.) Language and Communication (pp. 191-227. London: Routledge.

Segalowitz, N., Gatbonton, E. and Trofimovich, P. (2009). Links between ethnolinguistic affiliation, self-related motivation and second language fluency: Are they mediated by psycholinguistic variables? In Dörnyei, $\mathrm{Z}$ and Ushioda, E (Eds.), Motivation, language identity and the L2 self. (pp. 172-192). Clevedon: Multilingual Matters.

Schmitt, N. (ed). (2004). Formulaic sequences: Acquisition, processing and use. Amsterdam : John Benjamins.

Schmitt, N. (2013). Formulaic Language and Collocation. The Encyclopedia of Applied Linguistics. Wiley Online Library.

Schmitt, N. (2014). Size and depth of vocabulary knowledge. What the research shows. Language Learning, 64(4), 913-951.

Sinclair, J. (1991). Corpus, Concordance, Collocation. Oxford University Press.

Speciale, G., Ellis, N.C. and Bywater, M. (2004). Phonological sequence learning and short-term store capacity determine second language vocabulary acquisition. Applied Psycholinguistics 25. 293-321.

Stengers, H. (2009). The Idiom Principle put to the test: An exercise in Applied Comparative Linguistics. Unpublished $\mathrm{PhD}$ dissertation. Vrije Universiteit Brussel.

Stengers, H., Boers, F., Housen, A. (2011). Formulaic sequences and L2 oral proficiency: Does the type of target language influence the association?, International Review of Applied Linguistics in Language Teaching, 49(4), 321-343.

Wray, A. (2002). Formulaic Language and the Lexicon. Cambridge : Cambridge University Press. 